\title{
Miscellaneous Occupation
}

National Cancer Institute

\section{Source}

National Cancer Institute. Miscellaneous Occupation. NCI Thesaurus. Code C20192.

A listing of occupations that don't fall under another major heading. 